Global Sustainability

cambridge.org/sus

\section{Intelligence Briefing}

Cite this article: van der Leeuw S (2020). COVID-19 and the role of information processing. Global Sustainability 3, e27, 1-5. https://doi.org/10.1017/sus.2020.22

Received: 28 June 2020

Revised: 6 August 2020

Accepted: 7 August 2020

Keywords:

COVID-19; future developments; information processing; sustainability; weakening societal systems

Author for correspondence:

Sander van der Leeuw,

E-mail: vanderle@asu.edu

\title{
COVID-19 and the role of information processing
}

Sander van der Leeuw (1)

ASU-SFI Center for Biosocial Complex Adaptive Systems, Arizona State University. Engineering Research Center Building A, 1031 S. Palm Walk, PO Box 872701, Tempe AZ 85287-2701, USA

\begin{abstract}
The various crises that have emerged since 2000 are driven by an increasing maladaptation of our societies' information processing capabilities to the dynamics in which our societies find themselves. These capabilities have been built up path dependently over centuries, and to understand them we need to look closely at their history. Changes in technology, demography and resource use and environmental change are all part of a co-evolution in which societies' information processing capacities play a central role. The information and communications technology revolution has accelerated developments in all of these domains and has weakened some fundamental institutions. This paper discusses how these processes might affect the long-term future of our societies.
\end{abstract}

\section{Social media summary}

How will what we learn from COVID-19 about our society's information processing affect our future?

\section{Introduction}

The current COVID-19 crisis is one of a succession of crises that have shaken our world since 2000. The first was the attack on the Twin Towers in New York, concerning the political and religious domains. It was followed by the financial crisis of 2008-2009. The COVID-19 pandemic is the third major crisis in 20 years, concerning human health. This succession of crises is not accidental - it confronts us with the fact that our global 'system' is showing major fracture lines. Whereas the first two crises are without doubt anthropogenic, the core question about the COVID-19 pandemic is in how far it is of human origin. The anthropologist of nature Philippe Descola put this question recently (21 May 2020) in Le Monde in the following form: "Have humans become a virus in the environment?" In thinking about the years ahead, I look at the pandemic (and other coming crises) from an 'inside' perspective, affirming that such crises are experienced as well as caused by humans.

\section{The approach}

Human beings differ from most other animal species in that they can learn and learn how to learn (Bateson, 1972), but also in that they can categorize, make abstractions and hierarchically organize them, and communicate among themselves by symbolic means. Human learning involves the recognition of patterns of all kinds, whether temporal, spatial, semantic, syntactic or yet others. By identifying such patterns, human learning organizes the world, infuses it with structure and meaning, creates understanding and knowledge, intervenes in it, etc. Consequently, human beings can transform their natural and material environment in many different ways and at many spatial and temporal scales.

Our societies' relations with their environments are part of that uninterrupted process of human learning, which may be seen as a positive-feedback loop that creates order out of experiences of the - seemingly chaotic - world by isolating patterns, defining them in terms of a limited number of dimensions and storing the latter in the form of knowledge according to the following process (van der Leeuw, 2007):

Problem-solving structures knowledge $\rightarrow$ more knowledge increases the information processing capacity $\rightarrow$ that in turn allows the cognition of new problems $\rightarrow$ this creates new knowledge $\rightarrow$ knowledge creation involves more and more people in processing information $\rightarrow$ this increases the size of the group involved and its degree of aggregation $\rightarrow$ this creates more problems $\rightarrow$ this increases need for problem-solving $\rightarrow$ problem-solving structures more knowledge ... etc.

The more cognitive dimensions that exist, the more problems can be tackled and the more quickly knowledge is accumulated. This accumulation of information processing capacity 
enables a concomitant increase in matter, energy and information flows through a group or society, enabling its participants to grow in number. Hence, I see human societies as 'dissipative flow structures' in the sense of Prigogine (1980): dynamic structures dependent for their existence on flows of energy, matter and information that, due to their information processing, dissipate entropy. In the process, they align the sum total of the understanding, know-how and skills of the people involved, including their technical and organizational means of solving problems, to maintain group cohesion.

I thus view Anthropocene climate change not as an environmental, exogenous and 'objectifiable' challenge, but as a societal, endogenous one, related to a society's information processing capacity. The environment does not tell societies what to do. Societies define what they consider as their environments, they define what they see as challenges in those environments and they devise potential solutions for these challenges. Or, as Luhmann (1989, p. 35) has phrased it, "[S]ocieties do not exchange information with the environment, they exchange information about the environment among themselves, in a self-referential manner." Hence, in the Anthropocene, the environmental conditions (including climate change) are primarily consequences of human perception and action, even though they also have consequences for human life on Earth.

If we accept this, we can argue that it is the role of a society to deal with the environmental conditions it is facing, including those that are unintended consequences of its actions. If it does not or cannot do so, a society is doomed. Those unintended consequences are critical. Because of the difference in dimensionality between human perception and human action (in which perception concerns only a limited and biased set of dimensions and action confronts that limited perception with the unlimited dimensionality of the environment's dynamics), all human actions will always generate unanticipated consequences (van der Leeuw, 2012).

From the endogenous perspective developed here, a crisis or 'tipping point' could then be defined as "a (temporary) incapacity of a society's information processing to deal with the dynamics in which that society is involved" (van der Leeuw, 2020, p. 334). The effect can be illustrated by referring to a bank run in 2008 or the current epidemiological crisis. In both cases, the event was endogenous because, before it occurred, available information was ignored, not (yet) available or unobtainable, so that the society's information processing was not in tune with the dynamics that were occurring in its environment.

Rather than attempting to transform the environment, the way to deal with such a tipping point is therefore the adaptation of the society's information processing to the dynamics causing the crisis. Societies need to learn from events and change how they interact with their environment. When viewed from this angle, the reorganization of our societies' current information processing apparatus, based on learning from the events that have occurred, will be determinant for the future of our societies.

That is nothing new. Human societies have always adapted their information processing to changes in their environments, whether insufficient information, information overload, environmental crises, wars, economic imbalances, revolutions or pandemics. Some of these adaptations went almost unnoticed, such as the introduction of fossil energy that led to innovations in the material and energetic domains, changing the lives of many of us. This also transformed our information processing capacity, including our values, our goals and our institutions in ways that we are in part unaware of. To meet the needs of our changed circumstances and re-establish the adequacy of information processing, we need to revisit these changes.

\section{The many roles of information processing}

To achieve these goals, we will first need look at the role of information processing in domains threatening our societies' continued existence on Earth: (1) technology, (2) demography, (3) globalization and (4) climate change.

The first point to make concerns the acceleration of information processing itself. Because there is a limit to individual information processing in the short-term working memory, once problems become complex, they need the collaboration of more people to be solved, but at the same time more people cause, and perceive, more problems, so there is a positive-feedback loop. That feedback loop is, in my opinion, responsible for what sustainability scientists call 'The Great Acceleration', which affects all of the following domains.

An important aspect of the relationship between information processing and technology is that technology is both the product of information processing and an extra-somatic means of information processing. Over the long term, more and more of any society's information load is minimized by designing tools that shape human actions without the need for individuals to think about them. This is the case for stone tools in the distant past, but also for modern cars. But whatever the technology used, until the information and communications technology (ICT) revolution, active information processing remained the domain of humans.

In the late 1900s, by identifying information, alongside energy and matter, as one of the three basic commodities that constitute the flow structures at the core of human societies, information processing became both the object and the subject of itself in a process of self-reflection (Gleick, 2011)! In 50 years, this created an instant global communication network, enabled automated information processing and infinite information storage, and more recently automated information analysis and decision-making. For the first time in human history, active information processing was delegated to technology, cutting humans out of the loop. Artificial intelligence and programming generated by algorithms enabled a huge acceleration in both information processing and the development of technology.

In the domain of demography, that acceleration in information processing capacity and the rapid advances in science and technology that are part of it have powered the acceleration of an ongoing trend: the rapid increase in the global population and the resource use that comes with it. The world's population grew from 3.6 billion in 1969 to 7.7 billion in 2019. This more than doubling of the world's population placed serious stresses on the processing of information in our societies. These stresses could only be accommodated by enhanced (mainly electronic) methods of information processing, contributing to major changes in our societies' organization (automatization, the World Wide Web, social networks, tele-working, the surveillance economy).

Earth Overshoot Day, the day on which humanity uses up all of the resources that the Earth can produce in a year, was moved from 1 January 1969 to 4 August 2019. This is the result of the explosion of technology that went hand in hand with demography and the need to process more information. Technology and the use of science and technology in a competitive race towards 
ever higher rates of resource extraction and manufacturing for consumption - the current capitalist-driven economic activity growth - led to the increasing materialization of our existence. To deal with the explosion in material goods, the 'Internet of Things' is beginning to control information flows between the human-made objects in our environment as part of the geopolitical battle for economic, technological and strategic-military dominance.

The ICT revolution, in turn, accelerated globalization, linking the world through ever faster flows of information, money and goods, enabling long-distance just-in-time supply chains and the distance managing of production. The ability for everyone to actively communicate with everyone else worldwide, individually or collectively, has enabled the creation of non-territorial communities that do not coincide with spatially defined information processing networks such as governments and have made it difficult to distinguish information sources. The resultant multinationals have managed to grow by avoiding territorial rules and taxes.

As regards climate change, the ICT revolution contributed in two ways. On the one hand, it led to an increase in per capita resource use as part of the technological, social and economic revolution of the last 70 years. And on the other hand, the increase in worldwide communication drew more and more people into the materialist culture of the developed nations. The net effect has been a major acceleration in resource use and its counterpart, pollution.

In parallel, the possibility of hugely increasing our insights into the dynamics of climate change offered by the ICT revolution was mainly directed at identifying the environmental consequences of these developments, rather than their societal drivers, in an attempt to find ways to reduce the impact of the changes while maintaining the values and societal dynamics that caused them. Currently, we therefore have insufficient information about the societal values, beliefs and dynamics involved (van der Leeuw, 2020).

From an information processing perspective, the ICT revolution created the possibility for everyone in the world to communicate individually or collectively with everyone. This eroded the traditional capacity of individuals to distinguish between signals (information they trusted, which reinforced their values) and noise (information that did not fit their values). From a limited set of collectively accepted sources of information, such as acknowledged high-quality newspapers and television programmes, societies developed an explosion of alternative information sources, making it difficult to know which information to trust. From a degree of societal control over information, the world moved to a state without control over information. This accelerated a range of ongoing processes and brought them simultaneously to a head (for a more extensive treatment, see van der Leeuw, 2020):

- The undermining of the international diplomatic order, established in Europe in 1648 and based on autonomy (noninterference in other countries) and balance of power. The most evident sign of this is the cyber-meddling of certain states in others' politics and elections.

- The undermining of the democratic governance systems of many countries, where political parties are no longer needed to win elections, being replaced by massive databases containing political, economic and personal data about all citizens.
- The undermining of communities in Western countries due to the increased individualization that is promoted by urbanization and social networking over the Web, while in developing countries the same is promoted by the fact that they are drawn into globalization through the capitalist perspective (de Vries \& Revi, 2006).

- The increasing blending between the realm of imagination and that of reality through television 'reality' shows, computer games and social media, in which more and more hours are spent on algorithm-based interactions that encompass many fewer dimensions than reality.

- The increasing disappearance of a sense of place, because everyone can communicate without any reference to physical location.

Altogether, these and other developments have substantially weakened some of the institutions on which, in the 'developed' countries in particular, our societies are based.

\section{How about the future?}

The COVID-19 pandemic is one more stress test for our systems, highlighting the fracture lines in our societies (Schlosser et al., 2020). Because - all other things being equal - the pandemic's spread is density dependent, it affects cities in greater numbers than the countryside, accentuating the vulnerability of urban systems. Rather than assume the continued growth of cities, we might therefore see a degree of emigration from cities to the countryside as the ICT revolution removes a major driver of urbanism - the increase in collective information processing achieved in dense settlements. The move towards distance working in business due to COVID-19 might be the beginning of such a trend.

Another such potential fracture line is the use of ICT to improve health control. ICT is an essential part of the personalization of medicine through the use of personalized genetic analysis, and it can indeed contribute to health management. But ICT is also a major control and surveillance tool, so it requires a clear political focus to limit its use to its positive aspects. Many specialists are afraid that, in the current context, using ICT in the medical field will facilitate abuse of personal data, such as by the medical insurance industry.

But we are only at the beginning of the ICT revolution and have no insight into what comes next. Many authors are devoting attention to future role of ICT in this context (e.g., TWI2050, 2019). Little attention is paid in our 'progress' culture to the negative effects of technology (Hüsemann \& Hüsemann, 2011) and to the fact that solutions always create unanticipated problems (van der Leeuw, 2012). Often, solutions focus on the shorter term, while the problems they cause show themselves much later. Detailed assessment of the role of ICT is therefore impossible. With all due reservations, therefore, I sketch some ways in which information processing may affect possible futures.

As mentioned above, our world is engaged in simultaneous disintegration at many levels. The COVID-19 pandemic reinforces emerging fracture lines in the USA and the European Union, reducing top-level control and devolving governance to smaller organizational entities. How far will this process go? Could we, for example, see cities become the main centres of governance? Such devolution might also weaken government vis-à-vis business because major corporations are widespread, integrated and powerful across boundaries. 
The current pandemic has highlighted the emergence of nationalism and populism. Globalization has mainly been focused on only one dimension of information and value: money. It has thus reduced the diversity of values that is needed for people to both feel comfortable identifying with a group and experiencing their own individuality within it. Where those values have been crushed under globalization, people feel divorced from their place in the current world and hark back to earlier forms of governance. The pandemic reinforced awareness of this lack of belonging because the disease is of such local immediacy, triggering an experience of local solidarity.

From the information processing perspective, urbanization has been driven by the need for larger and larger groups of people to deal with increasingly complex challenges more and more rapidly. Cities' infrastructures are very expensive to maintain, and their density has many negative effects, such as disease spread, pollution, crime and poverty. As transportation and infrastructure costs rise and cities' footprints grow, middle- and upper-class populations initially, but ultimately also others, might migrate to smaller cities and the countryside through using distance working, engaging increasingly with the local economy.

An important degree of chaos will therefore persist in the next decades. Although it will take time, I assume that this will ultimately lead to global societal alignment in a number of communication networks around their ideas and values. This has happened many times in the past, and we know from multiplayer computer games that groups of people in a new environment create adapted values and rules where there are none.

\section{The prospect of global governance}

Long-term history's lesson is that the construction of these networks occurs from the 'bottom up', building from local nodes to larger and larger entities (e.g., Duby, 1953). It has been interesting to see how, during the recent pandemic, the level of local interactions rapidly increased, creating a sense of community at that level. But due to electronic communication, such communities need not be geographically anchored, and one can expect this to occur at many levels.

One related question is whether ICT systems might enable a unique global governance system. To me, this seems highly improbable, firstly because the dimensionality of the unintended consequences of any solution will always exceed global society's information processing capacity (Helbing et al., 2017), and secondly because societally coherent decision-making is limited to groups below a certain size (Ostrom, 1990; Ostrom et al., 2007), while different environments require different kinds of management and culture. Both push towards spatial fragmentation of authority and localized experimentation. However, in such a polycentric situation, there will still need to be supra-regional coordination.

To map the de- and re-constructive process, it is useful to distinguish between four major communities: government, business, civil society and academia, each with its own networks, goals and dynamics. ${ }^{i}$ The first three are focused on solutions, and the interactions between them shape the tensions that will determine those societies' futures. Academia is focused on understanding causes and challenges and plays a contributing role. These interactions play out very differently within and between the networks that constitute societies.

The better aligned a processing structure, the more effective it might be, but because it is less diverse and flexible, a reaction against its control may be more violent. In many 'developed' democratic societies currently, business has an advantage in both respects over civil society and government, which have not been able to reach the degree of alignedness and adaptability of business. In more totalitarian societies, however, government may have the advantage, or a collaboration between business and government may emerge. In such cases, civil society plays much less of a role. The balance between these three pillars of society is a very delicate and unpredictable one, and such a balance has never been achieved for longer periods of time.

In the debate about the post-COVID-19 future, these factors impact on plans to implement a more egalitarian and environmentally friendly future, such as that sketched in the Sustainable Development Goals. Clearly, the focused informationgathering corporations such as Google, Apple, Facebook and Amazon (GAFA), Tencent, Alibaba, etc., here have a major advantage over governments because the information they have collected allows them to foresee (and influence) societal tendencies.

The outcome will partly be determined by the evolution of our environment, including climate change, biodiversity, waste management, etc., and the societal changes brought about by ICT. Most research has thus far focused on the global level. But the concrete effects of environmental change vary greatly between locations, and the ways of dealing with them by human societies vary equally greatly with nations' economies and cultures.

Author contribution. The whole paper is the work of the author.

Financial support. None.

Conflict of interest. None

Research transparency and reproducibility. N/A.

\section{Note}

${ }^{\text {i }}$ I would like to thank Professor Gary Dirks (ASU) for this insight.

\section{References}

Bateson, G. (1972). Steps to an Ecology of Mind. Ballantine Books.

De Vries, H.J.M. \& Revi, A. (2006). The Search for Leverage Points in a Sustainability Transition, Balaton Conference Paper, January 2006. Retrieved from https://www.researchgate.net/publication/261697304_The Search_for_Leverage_Points_In_a_Sustainability_Transition

Duby, G. (1953). La Société aux XIe et XIIe siècles dans la region mâconnaise. Editions EHESS

Gleick, J. (2011). Information: A Theory, a History, a Flood. Pantheon Books. Helbing, D., Frey, B. S., Gigerenzer, G., Hafen, E., Hagner, M., Hofstetter, Y., ... Zwitter, A. (2017). Will democracy survive big data and artificial intelligence? Scientific American, 23 February.

Hüsemann, M. \& Hüsemann, J. (2011). Techno-Fix: Why Technology Won't Save Us or the Environment. New Society Publishers.

Luhmann, N. (1989). Ecological Communication. University of Chicago Press. Ostrom, E. (1990). Governing the Commons. Cambridge University Press.

Ostrom, E., Janssen, M. A. \& Anderies, J. M. (2007). Going beyond panaceas. Proceedings of the National Academy of Sciences of the United States of America, 104(39): 15176-15178.

Prigogine, I. (1980). From Being to Becoming: Time and Complexity in the Physical Sciences. W.H. Freeman.

Schlosser, P., Laubichler, M., Edwards, C., Beschloss, S., Berman, N., van der Leeuw, S., ... White, D. (2020). COVID-19: the ultimate stress test for our global futures. Medium, 28 March. 
TWI2050 (2019). The Digital Revolution and Sustainable Development: Opportunities and Challenges. Report from 'The World in 2050' Initiative. Retrieved from http://pure.iiasa.ac.at/id/eprint/15913/

van der Leeuw, S. E. (2007). Information processing and its role in the rise of the European World System. In: R. Costanza, L. G. Graumlich \& W. Steffen (eds), Sustainability or Collapse? (pp. 213-241). MIT Press. van der Leeuw, S. E. (2012). For every solution there are many problems. The role and study of technical systems in socio-environmental co-evolution. Danish Journal of Geography, 112(2): 149-159.

van der Leeuw, S. E. (2020). Social Sustainability Past and Future: Undoing Unintended Consequences for the Earth's Survival. Cambridge University Press. 